\title{
A Contradiction Between Online Han Chinese Ethnic Nationalism and Feminism: The Rise of China and the Effect of Chinese Traditional Culture
}

\author{
Yijian Tan* \\ School of Social Science and Public Policy, King's College London, London, United Kingdom \\ "Corresponding author.Email: yijian.tan@kcl.ac.uk
}

\begin{abstract}
This essay is aimed to explore the relationship between online Han Chinese ethnic nationalism and Feminism. The strong opposition to feminism by radical Han nationalists has been frequently observed on Chinese social media. This essay uses case study method and correlation analysis to understand this phenomenon. By understanding of Han Chinese online nationalism, the paper hopes to have broader lessons of the fundamental contradiction between nationalism and feminism. This research finds that contemporary online extreme Han ethnic nationalism is against Feminism, but women Han nationalist online are also strongly against Feminism. In conclusion, this article deepens people's understanding of the relationship between nationalism and feminism. Moreover, the essay could be helpful to the policy makers to create better policies to enhance equality both between different ethnic groups and between two sexes. Admittedly, the paper is limited because the coding process might exist the basis of the researcher and the sample size of the female Han nationalist is limited. On the other hand, the lessons drawn from this research might not be fully applicable in other cases, as it depends on the country's specific factor and the features in different time periods. Scholars can also look into other countries' situation and different time periods in Chinese history for further studies.
\end{abstract}

Keywords: Feminism, China social media, Han Chinese Ethnic Nationalism Online.

\section{INTRODUCTION}

The international situation has changed in recent years, with the development of a global trend towards rightism, ultra-nationalism, and racism. From the UK Independence Party and the Scottish Independence Movement to Trump's “America First", nationalism has once again taken center stage. At the same time, this farright movement is often associated with misogyny and anti-feminism [1]. The confrontation between feminism and nationalism is not a new phenomenon. Since the 1980s, when women and feminism began to dialogue with nationalism at an academic level, feminist scholars have found in their research that nationalism is often complicit in patriarchy and stands in opposition to feminism [2]. Although nationalism has occasionally chosen to collaborate with feminism, this collaboration has often been unequal and feminism has often been subordinate and dominated by nationalism [3, 4]. However, the construction of patriarchy in nationalism and its opposition to feminism has resulted in its aggressive, exclusive and dominant character, making nationalism a recipe for violence and conflict. Only through a better understanding of the relationship between nationalism and women and feminism, a more peaceful, egalitarian and inclusive nationalism be constructed [5].

As a multi-ethnic country, China has a different kind of ethnic nationalism underneath the state nationalism. According to Yao, around the year 2000, extreme ethnic nationalism was already rampant in China. The madness of the Huang-Han Website and the Northeast Manchu Website were particularly present in people's minds, even though these two websites have since been closed [6]. With the development of media technology and the advent of the new media era, the medium of online extremist nationalism has shifted from forums to social media platforms such as Weibo, Douban and Zhihu. As Zhang \& Wei argued, online radical ethnic nationalism in the new media era is an extension of the previous radical ethnic nationalism, and reflects a new kind of fission and development [7]. Weibo, one of the most popular social platforms in recent years, users are more inclined to make public-related statements, making the whole platform 
more like a public discourse space, which is different from other social media platforms, such as Wechat. Moreover, Weibo users generally exist as independent virtual objects, as they are not associated with people connected with them in real life. Hence, their comments tend to be bolder and more extreme. As a result, more extreme ethnic nationalist discourse can be observed on the Weibo platform. While the rhetoric of contemporary online Han Chinese radical nationalists is certainly racist and nationalist, it is worth noting that their rhetoric also includes a great deal of anti-feminist and misogynistic content. Current research on extreme Han Chinese nationalism on the Internet has focused on its racist and separatist tendencies, while neglecting its misogynistic tendencies. This essay will try to address the attitudes of radical Han nationalism towards women and feminism in this context.

This essay will be divided into six sections. After the introduction, the article will examine existing literature about nationalism and feminism. Next, the paper will look at the explanation of such difficult relationship between nationalism and feminism. Then the research method and the data will also be presented. Subsequently, the analysis of the findings will be offered. In the end, the conclusion will shed light on further studies.

\section{ETHNIC NATIONALISM AND CYBER NATIONALISM}

Existing research on extreme Han nationalism in contemporary China has mainly focused on its racist nature, e.g., the research of Yao [6]. The study of Zhang \& Wei focuses on the policy responses to the phenomenon [7]. While Jin's research focuses on its impact on Chinese diplomacy, Leibold's research investigates its relationship with government policy [8, 9], while research on its sexist, misogynistic tendencies is lacking.

\subsection{Contemporary ethnic nationalism in China}

According to Yao, the development of ethnic nationalism in contemporary China is characterised by racism, exclusivity and extremism. It is not confined to any single ethnic group but exists in many different ethnic groups, including Han, Mongolian, Manchu and Zhuang [6]. Yao also indicates that the crystallisation of cultural nationalism shapes the process of the emergency of the ethnic nationalism, and that extreme ethnic nationalism on the Internet is only a product of its flourishing [6]. Furthermore, Yao stated the roots of the cultural nationalism can be traced back to the 1980s [6]. As Yao proposes, the possible reasons for the development of cultural nationalism into ethnic nationalism, in terms of cultural ideology, are dramatic social change and a double national identity crisis [6]. Both Leibold and Yao believe that the causes of contemporary extreme ethnic nationalism are linked to the ethnic policies of the Chinese Communist Party after 1978 [6] [10]. Yao suggests that, ideologically, China has not succeeded in creating a new supra-ethnic national history after erasing the national identity under the communist grand narrative [6]. On the other hand, as Zhang puts forward that, as other contemporary radical nationalisms do, contemporary Chinese ultra-nationalism is also rooted in communal anxiety about globalization, modernity, and the accompanying crisis of national identity [11].

\subsection{Contemporary online radical Han nationalism}

The development of contemporary extreme ethnic nationalism among the Han Chinese, who make up the most significant number of China's total population, has had a significant impact on Chinese society. Among them, the Hanfu (Han Clothes) movement, as a representative movement of extreme Han nationalism in recent years, has attracted the attention of many scholars. As Zhang argues, the essence of the Hanfu movement is to proclaim the superiority of Han culture from a Han nationalism perspective [11]. According to Chew \& Wang, the "Hanfu" itself, however, is used in the Hanfu movement only as a symbol of Han culture and a means to promote contemporary conservative Han nationalism [12]. As Hanminzu.com argues, the Hanfu movement should never be about Hanfu alone; to emphasize Hanfu without mentioning the Han revival and Han nationalism behind it is to detach the flesh from the soul [11]. Over the Hanfu movement, an extreme form of contemporary Han nationalism has been firmed. It is worth noting that both the Hanfu movement and the early days of extreme Han nationalism on the Internet were centered on Hanminzu.com (www.hanminzu.com). Although Hanminzu.com has already been shut down by Chinese government, its website set the tone, which is extreme, confrontational and exclusive, to develop contemporary extreme Han nationalism on the Internet [11]. The site's confrontational and exclusionary attitude is evident in its opinions on both international relations and ethnic minorities in China [12]. In terms of international relations, contemporary online radical nationalist forums have consistently emphasized: "If you are not one of our race, you have a different heart" [12]. What is implied behind this maxim is both a realist approach to international relations in which states or nations exist in an endless struggle with each other, and the only goal for all parties is to pursue national or ethnic interests [12]. At the same time this realist theory has been applied to China's domestic ethnic relations leading to a confrontational nature of domestic ethnic relations with a strong racist tendency [12]. At the same time, it emphasizes that the reason why China is lagging is because of the erosion of Chinese culture due to the invasion of foreigners (Mongols and Manchus), so the only way to solve China's contemporary problems and 
bring it back to the top of the world is to revive Chinese culture [11]. In fact, Hanminzu.com, Li Li, built this website to confront Manchu ultra-nationalism (as he was censored after posting on a Manchu nationalist website).

According to Zhang and Wei, it is worth noting that the platform for the dissemination of radical nationalism in contemporary China is mainly the Internet, so the parts of the Internet and the laws of communication have profoundly influenced and given rise to the characteristics of radical Han nationalism [7]. Zhang and Wei continue to argue that in the new media era, the new way of communicating online leads users to become the primary subject of communication [7]. Meanwhile, "user-fans" have become the basic communication unit and method [7]. These phenomena lead to a downward shift of discourse and an exponential increase in the speed of communication [7]. Meanwhile, the spread of hot topics has become more emotional and ignores the truth and facts [7]. The spread of extreme Han nationalism on the Internet also follows these same patterns. Namely, it emphasizes emotions and neglects truth and attributes, so it can only continue to grow and secure its growth by inciting feelings and encouraging confrontation [7]. In the process of inciting antagonism, extreme Han nationalists not only choose to start ethnic antagonism but also use sexism and objectification of women to incite gender antagonism [13].

\section{INTERSECTION OF NATIONALISM AND FEMINISM}

\subsection{The Introduction of Feminism in Nationalism Study}

Although nationalism was already being studied in European scholarship in the early nineteenth century [14], the earliest feminist thinkers, Christine de Pisan, also began to raise the cry of feminism in the fourteenth and fifteenth centuries [15]. However, it was not until the 1960 s and 1970s, when the feminist movement in the west gained momentum, that feminism began to engage in the dialogue with nationalism [5]. Yuval-Davis argued, before the intervention of feminist studies, mainstream nationalist studies had presupposed a gender-neutral stance in nationalism. Still, gender has always been an essential factor in the construction of nationalism [16]. Feminist scholars have introduced gender and feminist perspectives into nationalist studies, critiquing the socalled "gender-blindness" of nationalist studies [5]. They point out the gendered nature of nationalism, and explore the important role that gender plays in the development of nation-states, ethnic conflict, and the construction of nations [5]. Among them, Yuval-Davis and Anthias provide critical theories for feminist to analyze the nation construction, suggesting five ways in which women intervene in nation construction: (1) women are the procreators of ethnicity/nationality; (2) women are the reproducers of the nation-state/ethnicity; (3) women are the transmitters of national/ethnic culture and collective ideology; (4) women are the markers of ethnic/national distinctions and are the focus and symbol of the ideological discourses, which are used to construct, reproduce and change the structure of ethnic/national categories; (5) women are participants in military struggles, politics, economy and nationhood [17]. Based on this theory, Walby and Peterson have made their supplement. Walby emphasizes that women are not monolithic, that they are also class-divided, and significant differences in their attitudes and involvement in nationalism [18]. Peterson emphasizes that the construction of nationalism is based on the heteronormative family. Women usually serve for the reproduction of social relations and the family in the construction of nationhood [19]. From these theories it can be seen that in nationalism the role of women as reproducers is particularly emphasized, which leads to different symbolic meanings, such as: "mother of the nation", "mother of the motherland", etc. On this basis, the female body has been elevated to the status of national honor and has been placed under nation's control [20].

Gender is not only a tool for the construction of nationhood. It is also part of the nation-state and nationalism. Ranchod-Nilssonmary \& Tetreault, citing Rousseau's account of the origins of private ownership, draw an analogy between the sovereign state and the patriarchal family and find that they are essentially the same, i.e., independent from the other units of the outside world and resistant to harm from the outside and absolute control of the inside [21]. Thus, the essence of the nationstate is the extension of private patriarchy into national patriarchy. Likewise, nationalism, through its gendered construction and in the service of the nation-state, is essentially a masculinized ideology. The strong masculinity of nationalism makes it confrontational, dominant and exclusive, and thus a major cause of war in recent times [22]. At the same time, nationalism is at root in conflict with feminism. In practice, however, the relationship between feminism and nationalism is not simply a confrontation [17]. In particular, in colonial and semi-colonial Asia and Africa, feminism often chose to cooperate with and sometimes depend on nationalism [23]. Jayawardena has analyzed the feminist and nationalist movements in several Asian countries and found that the feminist movements in modern Asia did try to struggle for women's political and legal equality but, because of their dependence on masculinized nationalism, women's actions have not succeeded in rethinking and fighting against patriarchal family and social institutions [23].

\subsection{Nationalism and Feminism in China}

Placed in a Chinese context, the very word "Guojia (state)" in Chinese directly indicates the close 
relationship between the state and the family (patrilineal) [24]. On the other hand, the word "Guojia" also shows that in traditional Chinese culture, the family is connected to the state as a unit of population reproduction and, consequently, incorporates the female body and copy into the state's system [24]. The roots of this linkage, which connects the family to the state's politics, come from traditional Confucianism. Confucianism confined women within the family and limited them to a secondary position through social norms (e.g., the three subordinate virtues) and the restriction of social relations [23]. Nationalism was closely linked to the feminist movement in the modern Chinese revolutionary direction [23]. From the revolutionary and reformist movements in the late Qing dynasty, nationalists began to reflect on tradition. They wanted to raise the status of women in society to move China towards a progressive path [25]. In the 1911 anti-Qing movement, the revolutionary party supported the feminist movement, promised women the right to vote, and then betrayed it [25]. The Kuomintang, too, was firstly supportive of the feminist movement until the split of the First United Front in 1927, but, after the break, KMD turned reactionary [23]. At the same time, the Communist Party did consistently support the feminist movement and call on equality between men and women. In practice, however, there were still many problems of inequality between men and women in Communist's liberated area [26].

In the modern Chinese feminist movement, women's education has been a focus of attention. Wan Qionghua uses women's education as an entry point to explore the relationship between feminism and nationalism in modern China [27]. Wan argues, in the Chinese National Salvation Campaign, feminism has to relied on nationalism to gain legitimacy, while nationalism used the promotion of women's rights as a means to mobilize women to join the campaign [27]. However, Wan continues to argue that Nationalism and Feminism are fundamentally contradictory, as they have different political aspirations, historical perspectives and foundations of existence [28]. Wan concludes that the differences between the two are so great that they disagree on the subject of women's studies, whether the school should aim to educate a virtuous wife and mother or a good citizen [29].

However, the new-age ultra-Han nationalism has chosen to go in the exact opposite direction from feminism. Carrico, who uses the Hanfu movement as an entry point for a field study of radical Han nationalists in contemporary China, finds that gender differences and stereotypical images of men and women are deliberately emphasised in the Hanfu movement [13]. Women are portrayed in the Hanfu movement as passive "others", who are supposed to be subordinated to the traditional patriarchy of male dominance [13]. On the other hand, "female chastity" was seen as the key to the revival of the Han nation and the maintenance of "racial purity" [13].

\subsection{Nationalism-based Explanations for Anti- Feminism in the Non-West}

Jayawardena's Feminism and Nationalism in the Third World used the historical experience, from the late 19 th to early 20 th centuries, in several different countries in the third world, including Iran, Egypt, China, to illustrate that feminism does not have an ethnic identity. It was not imposed on the Third World by the West, but instead, women's ideology has changed with the changing historical conditions [23]. Nevertheless, things have changed in these years. Hovhannisyan used contemporary Armenia as an example and convey that nationalism in the global south strongly against feminism and genderism, as feminism and genderism endanger the national identity, social tradition, and national future [28]. However, as Bjork-James conveys, western white nationalists also strongly oppose feminism, as they believe feminism has threatened the traditional whiteness and national identity [1]. Instead, Bruno argues that nonwest countries are more resistant to feminism, as western feminism tries to impose a universal ideology, which contradicts local culture and resembles the colonialism they have suffered [29]. In that case, Bruno advised more heterogenous feminism should be established to embrace the different local cultures [29]. Bruno's argument has one assumption that the local cultures are not contradicted to feminism. Instead, Batista argues that Confucianism itself is directly opposed to feminism, as the social norm proposed by Confucianism and the sexism within Confucianism are conflicted with feminism's core values [30].

\subsection{Misogyny among women: Challenge for Feminism}

Johnson defines misogyny as psychology and phenomenon of contempt, hatred and prejudice against women, including social exclusion, masculinity, sexism and the objectification of sexuality. Still, misogyny is essentially "a cultural attitude of hatred for females simply because they are female" [31]. However, misogyny is not only found among men, but also within women. In the first chapter of her book Misogyny, Chizuko Ueno defines misorgyny as "female contempt" and goes further to state that misogyny manifests in men as "female contempt" and in women as "self-loathing" [32]. In addition to females' self-loathing, Chizuko Ueno's book finds that female misogyny can also be about placing oneself outside of the female sphere, as a bystander, and "othering" women other than women oneself, thus transferring misogyny to others [33]. The root cause is that women do not exist in a vacuum, but in the patriarchal society, and are constantly influenced by and internalize a patriarchal culture. Having internalized sexism, they choose to minimize the value of femininity, believe in gender bias in favor of men, and use the gender bias to value other women and themselves [34]. Applying 
the knowledge of misogyny to Chinese Internet research, $\mathrm{Xu}$ and Gao observed that the comments and bullet screens on Chinese self-media beauty videos were full of sexist discourse, even though the audiences for beauty videos were almost exclusively female [35]. Xu and Gao suggest three reasons for this phenomenon: 1 . the nature of expression on the internet 2 . It reflects the patriarchal culture and gender relations in online space 3 . the internalization of offline misogynistic culture [35]. On this basis, $\mathrm{Xu}$ and Gao argue that the freer and more open space for expression brought about by the new age of Internet technology cannot eliminate and mitigate the long-standing and pervasive influence of patriarchal society [35].

\section{METHODOLOGY}

Almost all current research on Han nationalism uses qualitative methods, while quantitative research is lacking. Although Carrico observes the desire for women to return to tradition in online extreme Han nationalism, he does not provide further quantitative analysis to prove his point. He does not examine the relationship between extreme Han nationalism and feminism [13]. Thus, this study aims to verify the attitudes of extreme Han nationalism towards women and feminism through data analysis.

\subsection{Data and Measures}

This paper uses a non-invasive observation method to conduct manual coding and content analysis. Using Sina Weibo (Chinese Twitter) as the observation platform, a combination of judgmental sampling and snowball sampling was used to select a sample of eight extreme Han nationalist Weibo influencers and their respective top 10 followers on the Weibo fan interaction list. However, due to Chinese social media's censorship and bot polling, the actual sample was 78 . The criteria for identifying the extreme Han nationalist Weibo influencers were: 1. a clear tendency towards Han supremacy in their tweets and the content related primarily to extreme Han nationalism 2. a fan base of 40,000 or more. In this paper, the content posted by 78 users has been tracked and read over time and coded in a holistic, analytical way.

The coding has measured users' age, province of registration, degree of originality and numbers of their tweets. The independent variable in this study is gender. For dependent variables, this study measured the attitudes of those users towards seven different issues, including women marrying foreigners, feminism, political correctness, China's family planning policy, resistance to marriage and giving birth, and traditional culture. Meanwhile, attitudes toward two specific opinions about feminism will also be measured as dependent variables, which include the stigmatization of feminism as female boxing and the idea that Chinese feminists are controlled or instigated by foreign powers. Meanwhile, this work has also measured these users' attitudes toward different social groups, including Black people and Muslims, as dependent varies.

Generally, the codes are divided into three main categories: users' personal information and usage habits, attitudes towards different groups of people and perspectives towards various social issues. Based on these codes, this paper will attempt to carry out a statistically significant correlation analysis. For correlation analysis, this study has used contingency tables to do the compare proportions test for the compare proportions test, which is used to see if the frequency of occurrence of a particular event, action, or intention varies between groups [36]. Furthermore, Chi-Square Test has been used for deciding whether there is a significant relationship between two categorical variables and how likely this distribution is due to chance [37].

\section{RESEARCH FINDINGS}

\subsection{Descriptive Statistics}

There were 78 valid samples in the study, of which 62 (79.5\%) were male and only $15(19.2 \%)$ were female, showing a very unbalanced gender ratio within the group. Among the valid sample, only 33 users filled in their age, of which 27 were between 20 and 40 years old, accounting for $81.81 \%$ of the known age group. By inference, this group is mainly made up of young adults. In terms of originality, $65.4 \%$ of users were purely retweeters. A one-sample t-test yielded an average of 7,559 tweets for the 78 users in terms of the number of the tweets. At the same time, only $14.1 \%$ of users in the sample regularly shared their personal lives. This shows that this group, despite a lack of originality, has a strong desire to express themselves on relevant topics, but only on relevant issues. In terms of the users' location, with a valid sample of 55, it is worth noting that the group may be clustered in terms of geographical distribution. Of these 55 users, seven are from Guangdong province $(12.7 \%)$, six from Jiangsu (10.9\%) and five from Sichuan $(9 \%)$. 


\subsection{Attitudes Towards Various Social Groups by Gender}

Table 1. presents attitudes towards various social groups by gender.

\begin{tabular}{llllll}
\hline & $\mathrm{VN}$ & $\mathrm{N}$ & $\mathrm{Neu}$ & $\mathrm{P}$ & $\mathrm{VP} * *$ \\
\hline Muslim & & & & & \\
Male (N=47) & $93.62 \%$ & $4.26 \%$ & $0 \%$ & $2.13 \%$ & $0 \%$ \\
Female(N=13) & $100 \%$ & $0 \%$ & $0 \%$ & $0 \%$ & $0 \%$ \\
All Respondents(N=60) & $95 \%$ & $3.33 \%$ & $0 \%$ & $1.67 \%$ & $0 \%$ \\
Black People & & & & $0 \%$ \\
Male (N=48) & $95.83 \%$ & $4.17 \%$ & $0 \%$ & $0 \%$ & $0 \%$ \\
Female (N=14) & $100 \%$ & $0 \%$ & $0 \%$ & $0 \%$ & $0 \%$ \\
All Respondents(N=60) & $96.77 \%$ & $3.23 \%$ & $0 \%$ & $0 \%$ & $0 \%$ \\
Ethnic Minorities & & & & $0 \%$ \\
Male (N=48) & $91.67 \%$ & $4.17 \%$ & $2.08 \%$ & $2.08 \%$ & $0 \%$ \\
Female(N=15) & $86.67 \%$ & $0 \%$ & $13.33 \%$ & $0 \%$ & $0 \%$ \\
All Respondents(N=63) & $90.48 \%$ & $3.17 \%$ & 4.765 & $2.59 \%$ & $0 \%$ \\
\hline
\end{tabular}

**Scale from very negative to very positive

Based on the Chi-Square Test result, there is no statistically significant relationship between gender and attitudes towards different social groups, which suggests

\subsection{Attitudes Towards Various Social Issues by} Gender that nationalists of different genders hold similar views on different social groups.

Table 2. Attitudes Towards Various Social Issues by Gender

\begin{tabular}{|c|c|c|c|c|c|}
\hline & $\mathrm{VN}$ & $\mathrm{N}$ & Neu & $\mathrm{P}$ & VP** \\
\hline \multicolumn{6}{|l|}{ women marrying foreigner } \\
\hline Male(N=47) & $93.62 \%$ & $6.38 \%$ & $0 \%$ & $0 \%$ & $0 \%$ \\
\hline Female $(\mathrm{N}=14)$ & $100 \%$ & $0 \%$ & $0 \%$ & $0 \%$ & $0 \%$ \\
\hline All Respondents $(\mathrm{N}=61)$ & $95.08 \%$ & $4.92 \%$ & $0 \%$ & $0 \%$ & $0 \%$ \\
\hline \multicolumn{6}{|l|}{ Feminism } \\
\hline Male(N=49) & $91.84 \%$ & $4.08 \%$ & $4.08 \%$ & $0 \%$ & $0 \%$ \\
\hline Female $(\mathrm{N}=13)$ & $76.92 \%$ & $15.38 \%$ & $7.69 \%$ & $0 \%$ & $0 \%$ \\
\hline All Respondents(N=62) & $88.71 \%$ & $6.45 \%$ & $4.84 \%$ & $0 \%$ & $0 \%$ \\
\hline \multicolumn{6}{|l|}{ Political Correctness } \\
\hline Male(N=50) & $98.00 \%$ & $2.00 \%$ & $0 \%$ & $0 \%$ & $0 \%$ \\
\hline Female $(\mathrm{N}=13)$ & $100 \%$ & $0 \%$ & $0 \%$ & $0 \%$ & $0 \%$ \\
\hline All Respondents $(\mathrm{N}=63)$ & $98.41 \%$ & $1.59 \%$ & $0 \%$ & $0 \%$ & $0 \%$ \\
\hline \multicolumn{6}{|c|}{ China's Family Planning Policy } \\
\hline Male(N=40) & $95.00 \%$ & $5.00 \%$ & $0 \%$ & $0 \%$ & $0 \%$ \\
\hline Female $(\mathrm{N}=14)$ & $85.71 \%$ & $14.29 \%$ & $0 \%$ & $0 \%$ & $0 \%$ \\
\hline All Respondents $(\mathrm{N}=54)$ & $92.59 \%$ & $7.41 \%$ & $0 \%$ & $0 \%$ & $0 \%$ \\
\hline \multicolumn{6}{|c|}{ Resistance to Marriage and Giving Birth } \\
\hline $\operatorname{Male}(\mathrm{N}=31)$ & $87.10 \%$ & $12.90 \%$ & $0 \%$ & $0 \%$ & $0 \%$ \\
\hline
\end{tabular}




\begin{tabular}{|c|c|c|c|c|c|}
\hline Female(N=12) & $75.00 \%$ & $16.67 \%$ & 0 & 0 & $8.33 \%$ \\
\hline All Respondents $(\mathrm{N}=43)$ & $76.74 \%$ & $7.89 \%$ & $0 \%$ & $0 \%$ & $2.33 \%$ \\
\hline \multicolumn{6}{|l|}{ Traditional Culture } \\
\hline Male $(\mathrm{N}=35)$ & $0 \%$ & $0 \%$ & $0 \%$ & $2.86 \%$ & $97.14 \%$ \\
\hline Female $(\mathrm{N}=12)$ & $0 \%$ & $0 \%$ & $0 \%$ & $8.33 \%$ & $91.67 \%$ \\
\hline All Respondents(N=47) & $0 \%$ & $0 \%$ & $0 \%$ & $4.26 \%$ & $95.74 \%$ \\
\hline \multicolumn{6}{|c|}{ The Stigmatization of Feminism as Female Boxing } \\
\hline Male $(\mathrm{N}=30)$ & $0 \%$ & $0 \%$ & $0 \%$ & $0 \%$ & $100 \%$ \\
\hline Female(N=14) & $0 \%$ & $0 \%$ & $0 \%$ & $0 \%$ & $100 \%$ \\
\hline All Respondents $(\mathrm{N}=44)$ & $0 \%$ & $0 \%$ & $0 \%$ & $0 \%$ & $100 \%$ \\
\hline \multicolumn{6}{|c|}{ The Idea that Chinese Feminists are Controlled or Instigated by the Foreign Power } \\
\hline Male(N=29) & $0 \%$ & $0 \%$ & $0 \%$ & $3.45 \%$ & $96.55 \%$ \\
\hline Female $(\mathrm{N}=13)$ & $0 \%$ & $0 \%$ & $0 \%$ & $0 \%$ & $100 \%$ \\
\hline All Respondents $(\mathrm{N}=42)$ & $0 \%$ & $0 \%$ & $0 \%$ & $2.38 \%$ & $97.62 \%$ \\
\hline
\end{tabular}

**Scale from very negative to very positive

Based on the Chi-Square Test result, there is no statistically significant relationship between gender and attitudes towards different social issues, which suggests that nationalists of different genders hold similar views on different social issues.

\section{ANALYSIS}

This research has two important findings: 1. online extreme Han Nationalism is completely against Feminism, 2. Almost all Han nationalists deeply agree with the traditional Chinese patriarchal system, including most female Han nationalism.

\subsection{Chinese Traditional Culture}

In this research, $95.7 \%$ of users, among all samples, strongly agree with traditional culture, which could be a factor that leads to $88.7 \%$ of Han nationalist users strongly against feminism, and no one in the sample agrees or strongly agrees with feminism. In traditional Chinese culture and the Confucian social system, women have been seen as the inferior sex. For instance, Confucian once said in the Analects that, Women(nüzi) and servants (xiao ren) are hard to deal with (Analects 17.25) [38]. Although there are other interpretations for this quote, such as who nüzi in here refers to young unmatured women or councubines, many scholars still argue nüzi means women [38]. Also, Xiaoren in Chinese has often been referred to as people who are morally or intellectually problematic [38]. Women are not seen as equal to their counterparts, the men in the same social class, in Confucius' mind [38]. Furthermore, Analects almost doesn't positively mention women in the whole book [30]. Confucian's ideal about women affects later generation's Confucian theorist. For instance, Dong Zhongshu, a Neo-Confucian scholar from the Han dynasty, conveyed that women are the polar opposite of men: submissive, weak, and jealous [30]. Sexual discrimination in Chinese traditional culture is not restricted to Confucianism. Daoism believes Yin and Yang construct the world. Yin is often thought as feminine and negative, while Yang is positive and masculine [39]. Naturally, these features are contradicted with feminism. Since most online Han nationalists strongly support traditional culture, it is not surprising that many of them are against feminism. On the other hand, the value of population reproduction has been reemphasized in online Han nationalism. 92.59\% nationalists in the sample are strongly firmly family planning policy, and $76.74 \%$ are firmly against the idea of resistance to marriage and giving birth. The central component of the ideal Confucian society is family [40]. Meanwhile, in traditional Chinese culture, having more children in the family would lead to greater prosperity [40]. Childbearing has been highly valued both by the family and society. However, in that case, woman bearing children is not for herself, but the family or the country. In other words, women's reproductive rights are controlled by the family and the government. Instead, contemporary feminism advocate women's reproductive rights should only be owned by themselves [41]. Given the fundamental contradiction between traditional Chinese culture and feminism, and the fact that Han nationalists have made it their mission to revive traditional culture, it is easy to understand why Han nationalists are vehemently opposed to feminism.

\subsection{Inner Contradiction between Nationalism and Feminism}

Essentially, nationalism is an ideology that fights for one nation's interest or one ethnicity, while feminism tries to fight for women's interest. Nationalism and feminism can only work together when women's 
interests are aligned with national interests. Although, in a few cases, the interests of nationalism and feminism coincide, as in the recent colonial period when both feminism and nationalism needed to resist foreign colonizers, in many more cases, feminism and nationalism conflict [23][42]. As Fan and Luo argued, the nation-state constructed by nationalism essentially is a form of national patriarchy [5]. Furthermore, Walby conveyed that the nation-state transformers the private patriarchy (family) to public patriarchy [43]. The pattern of dispossession in private patriarchy is individual, with the predator usually the husband or father; the way of dispossession in public patriarchy is collective, with the predator usually being the many men in the community [43]. To give a more specific example, as the model proposed by Yuval-Davis and Anthias suggested, similar to traditional Chinese culture, the most crucial role for women, from a nationalist perspective, is the mother [17]. In that case, women's value is still restricted within the traditionally "private" sphere. Instead, feminism wants to break the boundary between public and private, and provide women with more chance to work in the traditionally "public sphere" [44] [45]. Therefore, in most cases, feminism is contradicted with nationalism, as they pursue different things and fight for other groups' interests.

\subsection{Rise of China}

In this research, the finding shows $88.7 \%$ of Han nationalist users in the sample strongly against feminism. Although I have mentioned the inner contradiction between Nationalism and Feminism, it is notable that, in the history of the Chinese Revolution, the relationship between Feminism and Nationalism has not always been complicated. One of the most famous feminists in Chinese history, Qiu jin, is also a prominent Han nationalist [23]. Qiu and other early Chinese nationalists believe that Confucian culture leads to the decay of China and lagging behind the west [23]. Therefore, they try to learn from the west and reform Chinese culture. In this case, they consider feminism, as part of western culture, could benefit China. For example, they think educating Chinese women, which count as half of the whole Chinese population, to be a better citizen could help to build a better China [27]. However, with the Chinese fast economic development, new generation Han nationalists do not consider western culture more advanced than Chinese culture. Meanwhile, they believed traditional Han Chinese culture had been a crucial factor for China's great country in ancient history. Moreover, today's Chinese quickly development also benefited from traditional culture, as it helps to build today's China's success. For instance, Weibo user Dahanminzuwansui (Long Live Great Han Ethnicity) stated in his Weibo that, "We can respect this Western value of difference. China chooses to be rich and progressive, leaving poverty and stagnation to the west, which is also respectful of history"
[46]. Consequentially, feminism, as an ideology that comes from the West, has been considered as an obstacle to reviving Han Chinese. There is another more specific example for their attitudes towards feminism and western culture. When Weibo user Rujiagongyangxue talks about marriage law, he stated, "China's current marriage laws are increasingly copying Western concepts, labelled as progressive in terms of equality, but the marriage and family system in Western societies is already generally disintegrating, so if we copy their concepts to guide the marriage and family relations between the two sexes in China, will we not also suffer the same tragedy of disintegrating the marriage and family system? This is a question that Chinese sociologists and jurists seem to have never given much thought to!" [47].

\subsection{Misogyny}

The research findings have already shown that, among the sample, $76.92 \%$ of female users firmly against feminism, and $100 \%$ of female users use feminism's stigmatized designations in their tweets. Surprisingly, so many female Han nationalists would against feminism and stand with the patriarchal system, which is not in their interest. Many of the female Han nationalists even use insulting terms to describe feminists and those women who have married foreigners. These female Han nationalists' tweets fit Johnson's and Chizuko's definition of misogyny. They are similar to the misogynistic comments observed by $\mathrm{Xu}$ and Gao in the beauty section of self-publishing [31] [33] [35]. As stated before, misogyny is caused by a patriarchal society. As today people still lived in this environment, everyone cannot avoid having some sort of misogyny. Nationalism is an ideology often connected with the patriarchal system, so when female nationalists sink themselves into it, they are more likely to be influenced by patriarchal ideology. The vast majority of the tweets of the female Han nationalists in the sample were related to Han nationalism, indicating that they prioritized their identity as Han nationalists over other identities. As Sen conveyed, it would easily lead to radical behavior when one person prioritizes one identity over all the other identities [48]. When their identity as Han nationalists outweighs their identity as women, it is easy to understand why they publish misogynistic statements so frequently.

\section{CONCLUSION}

In summary, this essay has begun with a short introduction for providing a general preview. Then a brief literature review and possible explanation theory have also been provided. After that, the research method and the resulting data have been presented to quantitatively illustrate the tension between radical Han nationalism and feminism. In the end, the result has been analyzed and discussed. 
This essay intends to deepen the understanding of online radical Han nationalism, and tries to help people to better understand the relationship between feminism and nationalism. On the other hand, it also intends to provide useful insight for policymakers to generate better policies to increase gender equality and ethnic diversity.

Admittedly, this work has some limitations. On one hand, coding might be affected by researcher's personal view. On the other hand, because the sample size is limited and the sex ratio in online Han nationalist is unbalanced, there are not many female Han nationalists in the sample. Moreover, since this research is dependent on variables specific to contemporary online Han nationalism, the lessons learned here may not apply elsewhere.

For further studies, firstly, the user involved in this research deserved individually interviewed for conducting qualitative research, which could provide more insights about radical Han nationalists' inner thoughts and test the hypothesis proposed in this essay. Also, to fully understanding the phenomenon, it is worthwhile to explore other perspectives and reasons. Meanwhile, other different ethnicities' nationalism in different time periods and their attitudes toward feminism also deserve to study, which may help people obtain a more comprehensive understanding of the relationship between feminism and nationalism in different contexts.

\section{REFERENCES}

[1] Sophie Bjork-James, 2020, Racializing misogyny: Sexuality and gender in the new online white nationalism, https://doi.org/10.1002/fea2.12011.

[2] Robert E. Miller \& Rick Wilford, 1998, Women, Ethnicity and Nationalism: The Politics of Transition.

[3] Kumari Jayawardena, 2016, Feminism and Nationalism in the Third World.

[4] Jill Benderly, 1997, Rape, Feminism and Nationalism in the War in Yugoslav Successor States.

[5] Ruolan Fan \& Zhuangxiong Luo, 2014, Deconstruction and Reconstruction: A Literature Review on Foreign Nationalism Studies in the Feminist Perspective, https://www.cnki.com.cn/Article/CJFDTotalMZYJ201405010.htm.

[6] Xinyong Yao, 2012, Contemporary Chinese 'Ethnic Nationalism'

Observation, http://www.cqvip.com/qk/72094x/201001/8985656 8504849484848484951.html.

[7] Aijun Zhang \& Yina Wei, 2020, The Extension and Variation of Extremist Nationalist Public Opinion in Cyberspace and Its Response,
http://www.cnki.com.cn/Article/CJFDTotalZNZX202002025.htm.

[8] Wei Jin, 2014, Don't let two kinds of extremist nationalism tear Xinjiang apart, https://www.aisixiang.com/data/77273.html.

[9] James Leibold, 2016, Han cybernationalism and state territorialization in the People's Republic of China, https://journals.sagepub.com/doi/full/10.1177/0920 $203 X 16631921$.

[10] James Leibold, 2010, More Than a Category: Han Supremacism on the Chinese Internet, More Than a Category: Han Supremacism on the Chinese Internet on JSTOR.

[11] Xian Zhang, 2009, The "Hanfu Movement": Ethnic Nationalism in the Internet Age, https://www.1xuezhe.exuezhe.com/Qk/art/397991? dbcode $=1 \&$ flag $=2$.

[12] Matthew Ming-tak Chew \& Wang, 2012, Online Cultural Conservatism and Han Ethnicism in China, https://www.researchgate.net/publication/2680618 83_Online_Cultural_Conservatism_and_Han_Ethn icism_in_China.

[31] Aijun Zhang \& Yina Wei, 2020, The Extension and Variation of Extremist Nationalist Public Opinion in Cyberspace and Its Response, https://www.1xuezhe.exuezhe.com/Qk/art/397991? $\mathrm{dbcode}=1 \&$ flag $=2$.

[13] Kevin Carrico, 2017, The great Han: race, nationalism, and tradition in China today, The Great Han: Race, Nationalism, and Tradition in China Today on JSTOR.

[14] Guanghui, Xia, 2010, The Study of Contemporary Chinese Nationalism, https://oversea.cnki.net/kcms/detail/detail.aspx?file name $=2010138040$. nh $\&$ dbcode $=C D F D \&$ dbname $=$ CDFD2010\&v $=$.

[15] Elinor Burkett \& Laura Brunell, 2020, Feminism, feminism | Definition, History, Types, Waves, Examples, \& Facts | Britannica.

[16] Nira Yuval-Davis, 1997, Gender and Nation, Gender and Nation | SAGE Publications Ltd.

[17] Floya Anthias and Nira Yuval-Davis, 1989, Woman-Nation-State, https://doi.org/10.1007/9781-349-19865-8.

[18] Sylvia Walby, 2001, Gender Transformations, Gender Transformations - 1st Edition - Sylvia Walby - Routledge Book.

[19] Spike Peterson, 1994, Gendered Nationalism, https://doi.org/10.1080/10402659408425777. 
[20] Peter van der Veer, 1994, Religious Nationalism, Religious Nationalism by Peter van der Veer Paperback - University of California Press (ucpress.edu).

[21] Sita Ranchod-Nilsson and Mary Ann Tétreault, 2000, Women, States, and Nationalism: At Home in the Nation? .

[22] Jill Steans, 2013, Gender and International Relations: Theory, Practice, Policy.

[23] Kumari Jayawardena, 2016, Feminism and Nationalism in the Third World .

[24] Tamara Hamlish, 1999, Calligraphy, gender and Chinese nationalism, Calligraphy, gender and Chinese nationalism TAMARA HAMLISH | Taylor $\&$ Francis Group (taylorfrancis.com).

[25] Elisabeth Croll, 1980, Feminism and Socialism in China, Feminism and socialism in China (umich.edu).

[26] Ling Ding, 1942, Reflections on March 8, https://www.marxists.org/chinese/referencebooks/yanan1942/2-02.htm.

[27] Qionghua Wan, 2007, Between Women and the State - The Interconstruction and Collision of Feminism and Nationalism in the Early 20th Century,

https://www.cnki.com.cn/Article/CJFDTotalSPEC200702016.htm.

[28] Siran Hovhannisyan, 2019, Anti-Genderism in the Non-West: Looking from the Other Side, AntiGenderism in the Non-West: Looking from the Other Side | Engenderings (lse.ac.uk).

[29] Javier Pereira Bruno, 2009, Third World Critiques of Western Feminism Theory in the PostDevelopment Era, https://ucu.edu.uy/sites/default/files/facultad/dcsp/ western_feminy_theory.pdf.

[30] Juliana Batista, 2017, The Confucianism-Feminism Conflict: Why a New Understanding is Necessary, https://www.schwarzmanscholars.org/events-andnews/confucianism-feminism-conflict-newunderstanding-necessary/ .

[31] Allan G. Johnson, 2000, The Blackwell Dictionary of Sociology: A User's Guide to Sociological Language, The Blackwell Dictionary of Sociology: A User's Guide to Sociological Language, 2nd Edition | Wiley.

[32] Michael Flood, 2007, International Encyclopedia of Men and Masculinities, (PDF) International Encyclopedia of Men and Masculinities (2007) | Michael Flood - Academia.edu.
[33] Chizuko Ueno, 2010, Onnagirai: Nippon no misojin̄̄ (Misogyny), Onnagirai: Nippon no misojin̄̄ = Misogyny / Ueno Chizuko | National Library of Australia (nla.gov.au).

[34] Steve Bearman, Neill Korobov, and Avril Thorne, 2009, The Fabric of Internalized Sexism , https://www.google.com/url?sa=t\&rct=j\&q=\&esrc $=\mathrm{s} \&$ source $=$ web $\& \mathrm{~cd}=\& \mathrm{cad}=\mathrm{rja} \&$ uact $=8 \& \mathrm{ved}=2 \mathrm{ah}$ UKEwj93_vq4v_wAhU87uAKHSOMBYgQFjAA egQIBBAD\&url=https $\% 3 \mathrm{~A} \% 2 \mathrm{~F} \% 2 \mathrm{Fjiss}$. org $\% 2 \mathrm{Fd}$ ocuments $\% 2$ Fvolume_1\%2Fissue_1\%2FJISS_200 9_1-1_10-

47_Fabric_of_Internalized_Sexism.pdf\&usg=AOv Vaw0ZdHw52-DKCewHlmQOb8pM.

[35] Zhi Xu \& Shan Gao, 2019, Internalizing Sexism in the Autonomous Region for Women on the Internet-Female dislike in self-published beauty videos and critique,

http://cjjc.ruc.edu.cn/CN/Y2019/V41/I6/145.

[36] Vincent Nijs, 2019, https://radiantrstats.github.io/docs/basics/compare_props.html.

[37] Katie M. Springston, 2017, https://digitalcommons.butler.edu/cgi/viewcontent. cgi? article $=1083 \&$ context=bjur.

[38] Anne Behnke Kinney, 2017, Women in the Analects, Women in the Analects - A Concise Companion to Confucius - Wiley Online Library.

[39] [39] The Editors of Encyclopaedia Britannica, 2021, yinyang, yinyang | Definition, Meaning, \& Facts | Britannica.

[40] Xiaotao Jin, Yuebin Cao, and Raogeng Zhu, 2005, A test of the influence of Confucianism on our fertility culture, https://www.1xuezhe.exuezhe.com/Qk/art/7789738 ?dbcode $=4 \&$ flag $=2$.

[41] Lisa Smyth, 2002, Feminism and abortion politics: Choice, rights, and reproductive freedom, https://www.sciencedirect.com/science/article/pii/S 027753950200256X?casa_token $=$ rExjzQ5uyJQAA AAA:JxeQ6agTNHpjXp6zukx8U1YW_TDYBqC M2uDHoi2wG_M6WYU39yR6KsksUKqqIWAne XOuLNJH.

[42] Cynthia Cockburn, 1998, The Space Between Us: Negotiating Gender and National Identities in Conflict, https://www.bloomsbury.com/uk/thespace-between-us-9781856496179/.

[43] Sylvia Walby, 1996, Woman and Nation, https://sgp1.digitaloceanspaces.com/proletarianlibrary/books/0e886046f9f1fe01c3ba434104ba655 5.pdf. 
[44] Ruth Gavison, 1992, Feminism and the Public/Private Distinction, Feminism and the Public/Private Distinction on JSTOR .

[45] Sisterhood and After Research Team, 2013, Equality, work and the Women's Liberation Movement, https://www.bl.uk/sisterhood/articles/equalitywork-and-the-womens-liberation-movement.

[46] Dahanminzuwansui, 2021, https://m.weibo.cn/1423932667/461970644507188 9. https://m.weibo.cn/6283693211/463365187620372 6.

[48] Amartya Sen, 2007, Identity and Violence: The Illusion of Destiny, https://www.amazon.co.uk/Identity-ViolenceIllusion-Amartya-Sen/dp/0141027800. 